\section{Poor Understanding of Radiation Profiles in Deep Space Causes Inaccurate Findings and Misleading Conclusions}

\author{
Bevelacqua J. J. ${ }^{1 \oplus}$, Mortazavi S. M. J.2,3*๑
}

\begin{abstract}
The radiation environment in deep space, where astronauts are behind the shelter provided by the Earth's magnetosphere, is a major health concern. Galactic cosmic rays (GCR) and solar particle events (SPE) are two basic sources of space radiation in the solar system. The health risks of exposure to high levels of space radiation can be observed either as acute and delayed effects. Zhang et al. in their recently published paper entitled " $\gamma$-H2AX responds to DNA damage induced by long-term exposure to combined low-dose-rate neutron and $\gamma$-ray radiation" have addressed the effects of different cumulative radiation doses on peripheral blood cell, subsets of T cells of peripheral blood lymphocytes and DNA damage repair. These researchers exposed animals to low dose rate ${ }^{60} \mathrm{Co}$-rays at $0.0167 \mathrm{~Gy} \mathrm{~h}^{-1}$ for $2 \mathrm{~h} / \mathrm{d}$ and ${ }^{252} \mathrm{Cf}$ neutrons at $0.028 \mathrm{mGy} \mathrm{h}^{-1}$ for $20 \mathrm{~h} / \mathrm{d}$ for 15,30 , or 60 consecutive days. They reported that the mRNA of $\mathrm{H} 2 \mathrm{AX}$ increased significantly, and showed a positive correlation with dose. Despite strengths, this paper has several shortcomings such as poor definition of low dose radiation as well as space and reactor radiation environments. Another shortcoming of this paper comes from this point that blood cell studies do not represent the biological effects of ionizing radiation on the total body. Moreover, the effects of the human immune system and DNA repair mechanisms are not included in the study. The role of pre-exposures and induction of adaptive response phenomena in decreasing the risk of radiation in deep space missions are also ignored.
\end{abstract}

Citation: Bevelacqua J. J, Mortazavi S. M. J. Poor Understanding of Radiation Profiles in Deep Space Causes Inaccurate Findings and Misleading Conclusions . J Biomed Phys Eng. 2019;9(5):587-588. https://doi.org/10.31661/jbpe.v0i0.1021.

\section{Keywords}

Space Radiation; Gamma Rays; Neutrons; y-H2AX; Astronauts

We read with great interest the paper by Zhang et al. entitled " $\gamma$-H2AX responds to DNA damage induced by long-term exposure to combined low-dose-rate neutron and $\gamma$-ray radiation"[1]. The authors have addressed the effects of different cumulative radiation doses on peripheral blood cell (PBC), subsets of T cells of peripheral blood lymphocytes (PBL) and DNA damage repair. The animals received whole body irradiation with low dose rate ${ }^{60} \mathrm{Co}$-rays at $0.0167 \mathrm{~Gy} \mathrm{~h}^{-1}$ for $2 \mathrm{~h} / \mathrm{d}$ and ${ }^{252} \mathrm{Cf}$ neutrons at $0.028 \mathrm{mGy} \mathrm{h}^{-1}$ for $20 \mathrm{~h} / \mathrm{d}$ for 15,30 , or 60 consecutive days. The findings of their study showed that the mRNA of H2AX increased significantly, and positive correlation with dose was shown. Despite numerous strengths, the paper authored by Zhang et al. has several shortcomings as follows:

1. The low dose radiation (LDR) is not defined correctly "Humans are exposed to LDR during air or space travel, in areas of low-level contamination, in some workplaces (such as nuclear power stations), or during radiotherapy". Radiotherapy patients receive doses as high as 60-70 Gy while the dose either in air or space travel can be 6-7 orders of magnitude lower than radiotherapy [2-4]. Moreover, the average total dose received by workers at a commercial reactor is only about $2 \mathrm{mSv} / \mathrm{y}(30,000$ times less than doses in radiotherapy) [2-4].

2 . The space and reactor radiation environments are not defined correctly radiotherapy [2-5]. The author state " In some special environments (nuclear power stations and in space station), workers are exposed to long-term low-dose-rate neutron and $\gamma$-ray combined IR". Neither in a reactor nor in space environment, are radiation profiles limited to neutron and gamma radiation types [2-5]. For example, in reactor there is the risk of exposure to alpha (internal dose) and beta particles and in space journeys, high $\mathrm{Z}$ and energy particles (HZEs) play a very critical role in radiation risk estimates. In
${ }^{1} \mathrm{PhD}$,Bevelacqua

Resources, 343 Adair

Drive, Richland, WA

99352, USA

${ }^{2} \mathrm{PhD}$, Medical Physics

Department, School of

Medicine, Shiraz Univer-

sity of Medical Sciences,

Shiraz, Iran

${ }^{3} \mathrm{PhD}$, Diagnostic Imaging

Department, Fox Chase

Cancer Center, 333 Cott-

man Avenue, Philadel-

phia, PA 19111, USA

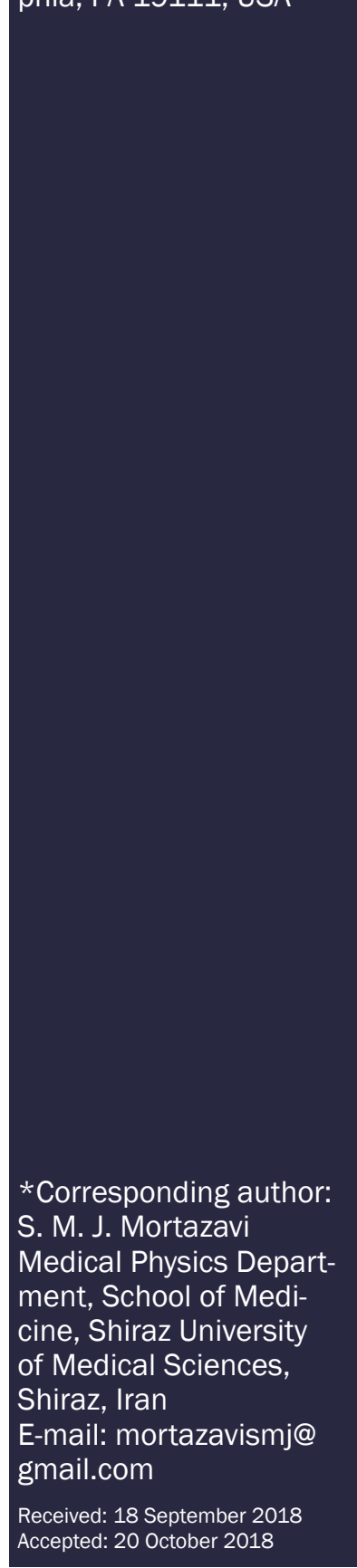


addition, the experimental conditions used in this study do not include microgravity, the duration of the space mission, and effects of radioadaptation. Moreover, the assumed dose of gamma and neutron radiation is not representative of the solar particle events (SPE) and galactic cosmic radiation (GCR) [2-7]. In this light, this cannot be a good rationale for designing a study on the combined effects of exposure to neutron and gamma.

3. Although most Generation II reactor dose is from ${ }^{60} \mathrm{Co}$, more recent generation II and Generation III reactors are dominated by ${ }^{58} \mathrm{Co}[2,3,5,6,8] .{ }^{58} \mathrm{Co}$ has a $0.811 \mathrm{MeV}$ photon while the average gamma energy of ${ }^{60} \mathrm{Co}$ is $1.25 \mathrm{MeV}$. Furthermore, these photons do not produce equivalent biological damage and radiation detriment. The delivered photon dose rate greatly exceeds the dose rate at a power reactor. In addition, workers are occupationally exposed for 2000 hours / year during their career which is not consistent with the experimental conditions. The spontaneous fission spectrum from ${ }^{252} \mathrm{Cf}$ is not equivalent to a power reactor neutron spectrum that is a combination of ${ }^{235} \mathrm{U}$ thermal fission, ${ }^{238} \mathrm{U}$ fast fission, and ${ }^{239} \mathrm{Pu}$ thermal fission [2-4, 6]. Only a small percentage of workers (primarily operators) receive any neutron radiation dose. Most workers receive dose from activation products [2-4]. The external doses are at power reactor of a combination of beta-gamma and neutron radiation subject to the conditions noted above. The delivered neutron dose used in the paper authored by Zhang et al. greatly exceeds the dose a worker receives in a year. The delivered doses in their paper exceed the occupational limits [3]. Therefore, these values are not representative of a power reactor environment.

4. Another shortcoming comes from the point that blood cell studies do not represent the biological effects of ionizing radiation on the total body. The experiment ignores radioadaptation to the radiation environment of a power reactor. The effects of the human immune system and DNA repair mechanisms are not included in the study. Radioadaptation increases the body's resistance to higher doses of radiation after a pre-exposure to a lower dose. The role of pre-exposures and induction of adaptive response phenomena in decreasing the risk of radiation in deep space missions has previously been discussed in detail by Mortazavi et al. [7-12]. Citing reports authored by Mortazavi et al. and other researchers about the importance of radioadaptation in deep space missions, a 2016 NASA report [13] states it is realistic to expect that cells will be exposed to multiple hits of protons before being traversed by an HZE particle. Moreover, a paper authored by a group of 30 scientists from US, Canada, UK, Russia, and Belgium [14] has also cited Mortazavi's papers and confirms the key role of biological protection of astronauts.

In summary, the paper authored by Zhang et al. has several shortcomings such as poor definition of low dose radiation as well as space and reactor radiation environments. Moreover, blood cell studies do not represent the biological effects of ionizing radiation on the total body. The effects of the human immune system and
DNA repair mechanisms are not included in the study. Furthermore, the role of pre-exposures and induction of adaptive response phenomena in decreasing the risk of radiation in deep space missions are also ignored.

\section{Conflict of Interest}

Authors declare no competing interests

\section{References}

1. Zhang J, He $Y$, Shen $X$, Jiang $D$, Wang $Q$, Liu $Q$, et al. $\gamma-\mathrm{H} 2 \mathrm{AX}$ responds to DNA damage induced by longterm exposure to combined low-dose-rate neutron and $\gamma$-ray radiation. Mutation Research/Genetic Toxicology and Environmental Mutagenesis. 2016;795:36-40. doi: 10.1016/j.mrgentox.2015.11.004.

2. Bevelacqua JJ. Health physics in the 21 st century: John Wiley \& Sons; 2008.

3. Bevelacqua JJ. Contemporary health physics: problems and solutions: John Wiley \& Sons; 2009.

4. Bevelacqua JJ. Health physics: radiation-generating devices, characteristics, and hazards: John Wiley \& Sons; 2016.

5. Bevelacqua JJ. Radiation protection consequences of the emerging space tourism industry. JJ Earth Science. 2017:1:1-11.

6. Bevelacqua JJ. Health physics aspects of generation IV reactors. International Nuclear Safety Journal. 2014;3:13-37.

7. Mortazavi SM. Space radiobiology and the new era of induced radioresistance: should traditional concepts be moved to science history museums? Technol Health Care. 2013;21:285-9. doi: 10.3233/THC-130732. PubMed PMID: 23949175.

8. Mortazavi S, Mozdarani H. Deep space missions and the issue of overcoming the problem of space radiation. International Journal of Radiation Research. 2013;11:199202.

9. Mortazavi SM, Cameron JR, Niroomand-rad A. Adaptive response studies may help choose astronauts for long-term space travel. Adv Space Res. 2003:31:154351. PubMed PMID: 12971409. doi: 10.1016/s02731177(03)00089-9.

10. Bevelacqua JJ, Mortazavi SMJ. Commentary: Human Pathophysiological Adaptations to the Space Environment. Front Physiol. 2017;8:1116. doi: 10.3389/ fphys.2017.01116. PubMed PMID: 29358922; PubMed Central PMCID: PMC5766677.

11. Bevelacqua JJ, Welsh J, Mortazavi SMJ. Comments on 'An overview of space medicine'. $B r$ J Anaesth. 2018;120:874-6. doi: 10.1016/j.bja.2017.12.015. PubMed PMID: 29576129.

12. Bevelacqua JJ, Mortazavi SMJ. Commentary: Immune System Dysregulation During Spaceflight: Potential Countermeasures for Deep Space Exploration Missions. Front Immunol. 2018;9:2024. doi: 10.3389/ fimmu.2018.02024. PubMed PMID: 30233600; PubMed Central PMCID: PMC6131484.

13. Huff J, Carnell L, Blattnig S, Chappell L, Kerry G, Lumpkins $S$, et al. Evidence report: risk of radiation carcinogenesis. 2016.

14. Cortese F, Klokov D, Osipov A, Stefaniak J, Moskalev A, Schastnaya J, et al. Vive la radioresistance!: converging research in radiobiology and biogerontology to enhance human radioresistance for deep space exploration and colonization. Oncotarget. 2018:9:14692-722. doi: 10.18632/oncotarget.24461. PubMed PMID: 29581875; PubMed Central PMCID: PMC5865701. 